\title{
The reproducibility of COPD blood eosinophil counts
}

To the Editor:

Post hoc and pre-specified analyses of chronic obstructive pulmonary disease (COPD) randomised controlled trials have shown that higher blood eosinophil counts predict greater inhaled corticosteroid (ICS) effects on exacerbation prevention [1-5]. COPD patients with higher blood eosinophil counts have greater eosinophil numbers in sputum, bronchoalveolar lavage and bronchial tissue, and more reticular basement membrane thickening [6]. Furthermore, increased sputum eosinophil counts are associated with reduced airway presence of pathogenic bacteria in COPD [7]. Eosinophilic COPD therefore has distinct biological features associated with increased ICS responsiveness.

ICS effects incrementally increase with higher eosinophil counts [1,3-5], rather than an "all or nothing" phenomenon. Thresholds of $\geqslant 300,150-<300$ and $<150$ eosinophils per $\mu \mathrm{L}$ appear to predict high, intermediate and low ICS response respectively $[8,9]$. While there is currently no consensus regarding the threshold(s) for use in clinical practice, it appears that $\sim 150$ eosinophils per $\mu \mathrm{L}$ is a key cut-off predicting little or no ICS response.

Blood eosinophil count variability may cause movement across a threshold, assigning an individual to a different ICS response category. Using historical data, we report the long-term reproducibility ( $>2$ years) of COPD blood eosinophil counts using $<150$ eosinophils per $\mu \mathrm{L}$ as a key ICS response prediction threshold.

Results from COPD patients aged $\geqslant 40$ years, diagnosed by Global Initiative for Chronic Obstructive Lunge Disease criteria [10], recruited for research studies at the Medicines Evaluation Unit (Manchester University NHS Foundation Trust, Manchester, UK) were used. Patients taking oral corticosteroids or with a previous asthma diagnosis were excluded. All patients provided blood samples $>4$ weeks from exacerbation. This research was approved by the local ethics committees (North West, Preston and Manchester South, UK; REC references 10/H1016/2, 10/H1003/108 and 06/Q1403/156); all patients provided written informed consent.

Blood eosinophil measurements (reported to two decimal places) were performed by The Doctors Lab (London, UK) or Wythenshawe Hospital clinical laboratory (Manchester, UK); normal eosinophil ranges for both laboratories were $<400$ eosinophils per $\mu \mathrm{L}$. Symptoms using the modified Medical Research Council scale (mMRC) and the COPD Assessment Test (CAT), health-related quality of life using the St George's Respiratory Questionnaire for COPD Patients (SGRQ-C), and exacerbation history were recorded, and lung function measurements performed.

Comparisons of repeat measures were by Spearman's rank correlation (Prism 7.0; Graphpad, San Diego, CA, USA), intraclass correlation coefficient (ICC) using log-transformed data, Bland-Altman analysis, assessment of heterogeneous variance and repeatability coefficient analysis [11] (SPSS 22.0; IBM, Armonk, NY, USA).

COPD patients $(\mathrm{n}=82)$ had a mean \pm SD age of $65.1 \pm 6.3$ years, a forced expiratory volume in $1 \mathrm{~s}(\mathrm{FEV} 1)$ of $57.7 \pm 17.2 \%$ predicted and an $\mathrm{FEV}_{1} /$ forced vital capacity ratio of $44.7 \pm 13.3 \%$. The median smoking history was 41.4 pack-years; $62 \%$ were ex-smokers. The mMRC, CAT and SGRQ-C scores were 1.9 $\pm 1.1,18.4 \pm 9.3$ and $40.3 \pm 25.2$ respectively.

Repeat blood eosinophil counts at baseline and 6 months $(n=55)$ showed there was a significant correlation $(\mathrm{rho}=0.80, \mathrm{p}<0.001)$ and an ICC of 0.89 . Repeat measurements at $\geqslant 2$ years $(\mathrm{n}=59$; mean 2.96 years, range 2.03-5.19 years) also showed a significant correlation ( $\mathrm{rho}=0.74, \mathrm{p}<0.001$ ) with an ICC of 0.87 (figure $1 \mathrm{a}$ ).

@ERSpublications

Blood eosinophil counts in COPD are stable over the long term http://ow.ly/aDlN30jVBCg

Cite this article as: Southworth T, Beech G, Foden P, et al. The reproducibility of COPD blood eosinophil counts. Eur Respir J 2018; 52: 1800427 [https://doi.org/10.1183/13993003.00427-2018]. 

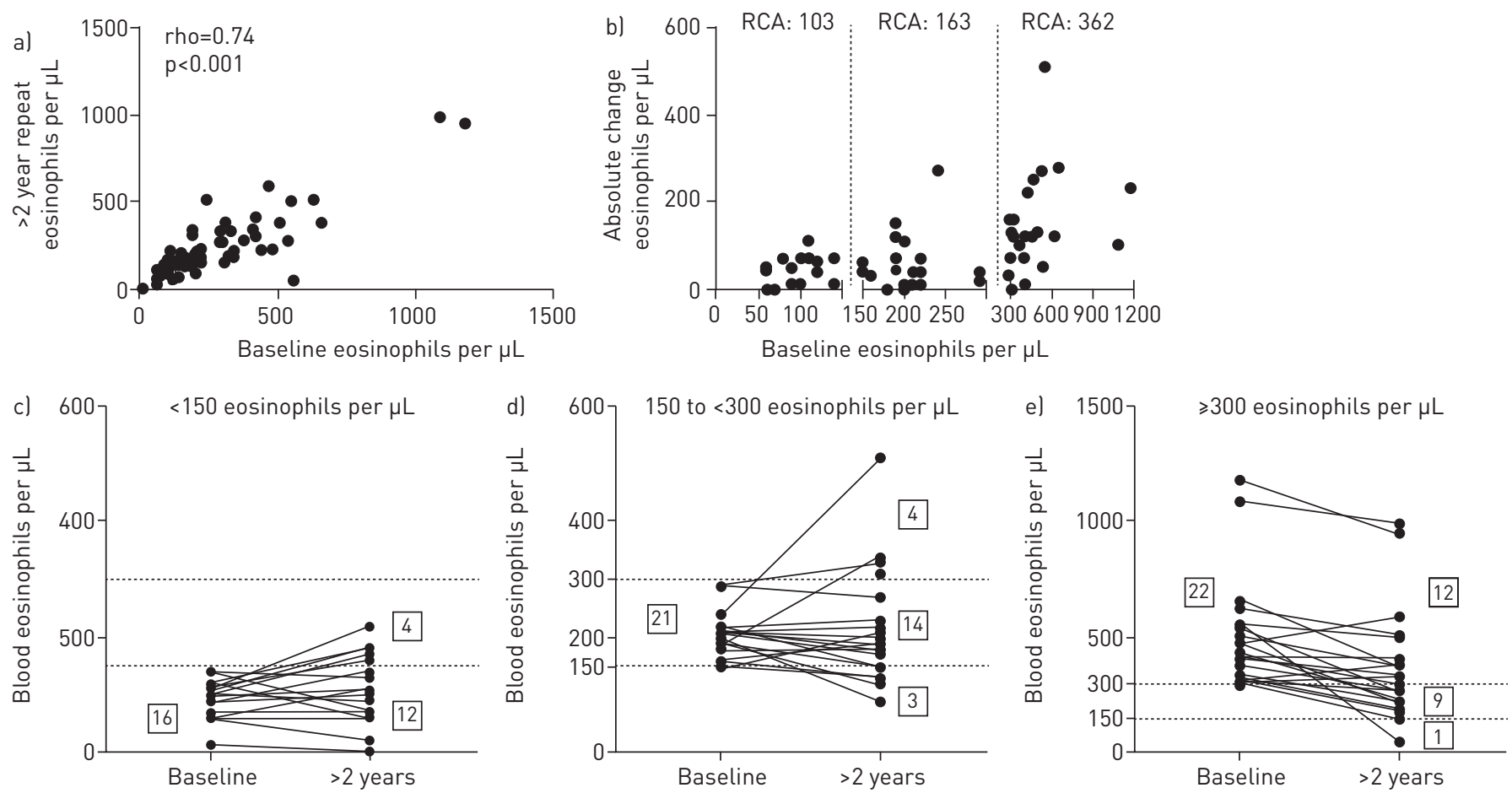

FIGURE 1 Variation of repeated measurements of chronic obstructive pulmonary disease blood eosinophils. a) Blood samples were collected at baseline and $>2$ years later. b) Baseline eosinophil samples were characterised as being either $<150,150-<300$ or $\geqslant 300$ eosinophils per $\mu \mathrm{L}$ for repeatability coefficient analysis (RCA), which predicts where $95 \%$ of the repeat values will fall. c-e) Changes in these categories from baseline during repeat measurements (c) $<150$, d) 150 to $<300$ and e) $\geqslant 300$ eosinophils per $\mu \mathrm{L}$ ). Boxed numbers describe the number of samples in each category. The dotted lines show the 150 and 300 eosinophils per $\mu \mathrm{L}$ cut-offs.

Bland-Altman regression analysis (6 months: $\mathrm{p}=0.006$; $>2$ years: $\mathrm{p}=0.015)$ and analysis of heterogeneous variance indicated that mean differences and variability between visits increased with higher blood eosinophil counts. We therefore calculated repeatability coefficients for $<150,150-<300$ and $\geqslant 300$ eosinophils per $\mu \mathrm{L}$; $95 \%$ of repeat measurements at 6 months fell within 106, 160 and 470 eosinophils per $\mu \mathrm{L}$ respectively, with similar data observed at $\geqslant 2$ years (figure $1 \mathrm{~b}$ ). The larger eosinophil count changes were not associated with changes in ICS use.

Using the $<150$ eosinophils per $\mu \mathrm{L}$ threshold, at 6 months there were 48 (87\%) out of 55 results that remained stable above or below this level, while at $>2$ years, $51(86 \%)$ out of 59 results showed stability (figure 1c). The $>100$ eosinophils per $\mu \mathrm{L}$ threshold (proposed to predict positive ICS treatment effects [1]) also provided similar stability results $(91 \%$ and $85 \%$ stability at 6 months and $>2$ years respectively). We evaluated reproducibility using the $\geqslant 300,150-<300$ and $\leqslant 150$ eosinophils per $\mu \mathrm{L}$ thresholds (figure $1 \mathrm{c}-\mathrm{e}$ ); at $>2$ years, $38(64.0 \%)$ out of 59 measurements remained in the same category, with one (1.7\%) patient moving between the lowest and highest category, seven (12\%) moving between lowest and middle categories, and $13(22 \%)$ moving between the middle and higher categories. Similar reproducibility was observed at 6 months; 39 (71\%) out of 55 measurements remained within the same category, with seven (13\%) measurements moving between the lowest and middle categories, and nine (16\%) between the middle and highest categories.

In summary, the majority $(\geqslant 86 \%)$ of blood eosinophil measurements repeated at 6 months or $>2$ years remained in the same category using the 150 eosinophils per $\mu \mathrm{L}$ threshold. This indicates good long-term biomarker stability in most individuals using this single threshold.

Statistical analysis showed greater variability at higher blood eosinophil counts. The decreased variability at lower eosinophil thresholds explains why the majority of results remained stable at $\leqslant 100$ or $<150$ eosinophils per $\mu \mathrm{L}$. The greatest variation was observed $\geqslant 300$ eosinophils per $\mu \mathrm{L}$, although only one patient moved between the lowest and highest categories $(<150$ and $\geqslant 300$ eosinophils per $\mu \mathrm{L}$ respectively). Variation between the middle and highest categories should not cause many problems with clinical interpretation, as both categories predict a positive ICS response [3, 9].

$12.7 \%$ and $13.6 \%$ of results that moved between the $<150$ eosinophils per $\mu \mathrm{L}$ category and the other categories at 6 months and $>2$ years respectively. These results are more difficult to interpret in clinical 
practice, varying between predicting a low response, suggesting ICS should not be used, to predicting a positive response favouring ICS use. Other clinical factors should also be used to make individual decisions about ICS use, including risk of side-effects and any previous clinical history of ICS response. Nevertheless, our results demonstrate that $>86 \%$ of repeat eosinophil counts provide a clinically similar interpretation regarding ICS response prediction using thresholds of either 100 or 150 eosinophils per $\mu \mathrm{L}$.

Repeat measurements at 6 months and $>2$ years resulted in ICC values of 0.89 and 0.87 , respectively. Other COPD studies have reported ICCs of 0.73 at 6 months $(n=145)$ [12] and 0.74 at 1 year $(n=17724)$ [13]. These results all closely match our own findings. These results can be influenced by the number of decimal places to which eosinophil counts were reported.

In the ECLIPSE study, the reproducibility of four blood eosinophil measurements over 3 years using a $2 \%$ threshold was reported; $51 \%$ of patients did not change category [14]. It is not ideal to compare results between studies using percentage and absolute counts. Multiple blood tests (as in ECLIPSE) increase the statistical probability that individuals might change category. In such instances, we suggest a practical approach to choose the category where most of the values lie.

CASANOva et al. [15] reported that $15.8 \%$ of COPD patients had consistent blood eosinophil counts $\geqslant 300$ per $\mu \mathrm{L}$ after 12 months (CHAIN cohort) and $12 \%$ after $>7.5$ years (BODE cohort). We observed $33 \%$ and $20 \%$ after 6 months and $>2$ years respectively. We had more patients with a baseline count $\geqslant 300$ eosinophils per $\mu \mathrm{L}$ (39\%) compared to the CHAIN (34.7\%) and BODE (26.6\%) cohorts. Moreover, we propose that using lower eosinophil thresholds (100 or 150 cells per $\mu \mathrm{L})$ provides more stable categorisation of eosinophil counts over time.

While our sample size was modest, we provide accurate information regarding movement across commonly used eosinophil threshold values. Nearly $90 \%$ of repeated measurements remained in the same category when using 150 eosinophils per $\mu \mathrm{L}$ to predict ICS response.

Thomas Southworth ${ }^{1}$, Gussie Beech ${ }^{1}$, Philip Foden $\odot^{2}$, Umme Kolsum ${ }^{1}$ and Dave Singh ${ }^{1}$

${ }^{1}$ The University of Manchester, Medicines Evaluation Unit, Manchester University NHS Foundation Trust, Manchester, UK. ${ }^{2}$ Medical Statistics Dept, Manchester University NHS Foundation Trust, Manchester, UK.

Correspondence: Dave Singh, The University of Manchester, Medicines Evaluation Unit, The Langley Building, Manchester University NHS Foundation Trust, Southmoor Road, Manchester, M23 9QZ, UK. E-mail: dsingh@meu.org.uk

Received: March 012018 | Accepted after revision: April 242018

Conflict of interest: D. Singh reports receiving personal fees from Apellis, Genentech, Cipla, Peptinnovate and Skyepharma, and grants and personal fees from Boehringer Ingelheim, Chiesi, GlaxoSmithKline, Glenmark, Menarini, Merck, Mundipharma, Novartis, Pfizer, Pulmatrix, Teva, Therevance, Verona and AstraZeneca, outside the submitted work.

\section{References}

1 Bafadhel M, Peterson S, De Blas MA, et al. Predictors of exacerbation risk and response to budesonide in patients with chronic obstructive pulmonary disease: a post-hoc analysis of three randomised trials. Lancet Respir Med 2018; 6: 117-126.

2 Vestbo J, Papi A, Corradi M, et al. Single inhaler extrafine triple therapy versus long-acting muscarinic antagonist therapy for chronic obstructive pulmonary disease (TRINITY): a double-blind, parallel group, randomised controlled trial. Lancet 2017; 389: 1919-1929.

3 Pascoe S, Locantore N, Dransfield MT, et al. Blood eosinophil counts, exacerbations, and response to the addition of inhaled fluticasone furoate to vilanterol in patients with chronic obstructive pulmonary disease: a secondary analysis of data from two parallel randomised controlled trials. Lancet Respir Med 2015; 3: 435-442.

4 Calverley PMA, Tetzlaff K, Vogelmeier C, et al. Eosinophilia, frequent exacerbations, and steroid response in chronic obstructive pulmonary disease. Am J Respir Crit Care Med 2017; 196: 1219-1221.

5 Siddiqui SH, Guasconi A, Vestbo J, et al. Blood eosinophils: a biomarker of response to extrafine beclomethasone/ formoterol in chronic obstructive pulmonary disease. Am J Respir Crit Care Med 2015; 192: 523-525.

6 Kolsum U, Damera G, Pham TH, et al. Pulmonary inflammation in patients with chronic obstructive pulmonary disease with higher blood eosinophil counts. J Allergy Clin Immunol 2017; 140: 1181-1184.

7 Kolsum U, Donaldson GC, Singh R, et al. Blood and sputum eosinophils in COPD; relationship with bacterial load. Respir Res 2017; 18: 88.

8 Roche N, Chapman KR, Vogelmeier CF, et al. Blood eosinophils and response to maintenance chronic obstructive pulmonary disease treatment. Data from the FLAME Trial. Am J Respir Crit Care Med 2017; 195: 1189-1197.

9 Singh D. Predicting corticosteroid response in chronic obstructive pulmonary disease. Blood eosinophils gain momentum. Am J Respir Crit Care Med 2017; 196: 1098-1100.

10 Vogelmeier CF, Criner GJ, Martinez FJ, et al. Global Strategy for the Diagnosis, Management, and Prevention of Chronic Obstructive Lung Disease 2017 Report: GOLD Executive Summary. Eur Respir J 2017; 49: 1700214.

11 Bland JM, Altman DG. Measuring agreement in method comparison studies. Stat Methods Med Res 1999; 8: $135-160$. 
12 Barker BL, Mistry V, Pancholi M, et al. Are sputum and blood biomarkers of inflammation repeatable in stable COPD? Thorax 2012; 67: A155-A1A6.

13 Landis SH, Suruki R, Hilton E, et al. Stability of blood eosinophil count in patients with COPD in the UK Clinical Practice Research Datalink. COPD 2017; 14: 382-388.

14 Singh D, Kolsum U, Brightling CE, et al. Eosinophilic inflammation in COPD: prevalence and clinical characteristics. Eur Respir J 2014; 44: 1697-1700.

15 Casanova C, Celli BR, de-Torres JP, et al. Prevalence of persistent blood eosinophilia: relation to outcomes in patients with COPD. Eur Respir J 2017; 50: 1701162. 